\title{
O Conteúdo Informacional das Transações no Mercado Futuro de Câmbio: Uma investigação do Caso Brasileiro
}

(The Informational Content of Trades on Foreign Exchange Futures: an Application to the Brazilian Market)

\author{
Vanessa Neumann Sulzbach* \\ João Mergulhão** \\ Pedro L. Valls Pereira***
}

\section{Resumo}

Modelos de microestrutura da taxa de câmbio têm recebido especial atenção nos últimos anos por capturarem de forma mais acurada as nuances deste mercado e evidenciarem a existência de informação assimétrica entre os agentes que transacionam nele. Os dados das operações do primeiro vencimento dos contratos futuros de câmbio Real/Dólar da Bolsa de Mercadorias e Futuros (BM\&F) foram utilizados para testar se as transações impõem efeitos informativos sobre os preços. Os resultados do modelo de vetor-autoregressivo (VAR) estrutural apontaram para a existência de informação assimétrica no mercado futuro de câmbio brasileiro, indicando que aproximadamente $50 \%$ da variação do preço eficiente é resultado da informação privada contida no fluxo de ordem. Além disso, a análise do fluxo de ordem permitiu a estimação das taxas de chegada de ordens de agentes informados e não informadas no mercado, utilizadas para calcular a probabilidade de uma transação ser informativa (PIN). Altos valores de PIN implicam spreads mais amplos que reduzem a liquidez do mercado. O resultado de $1,53 \%$ indica que o mercado de câmbio brasileiro é bastante líquido, o que impõe menores custos aos agentes menos informados que chegam ao mercado.

Submetido em 23 de novembro de 2015. Reformulado em 15 de dezembro de 2015. Aceito em 17 de dezembro de 2015. Publicado on-line em 20 de Abril de 2016. O artigo foi avaliado segundo o processo de duplo anonimato além de ser avaliado pelo editor. Editores responsáveis: Márcio Laurini e Márcio Garcia

*Fundação de Economia e Estatística e Escola de Economia de São Paulo-FGV Email: vane.sul@gmail.com

**Escola de Economia de São Paulo - FGV e CEQEF-FGV E-mail: joao. mergulhao@fgv.br

***Escola de Economia de São Paulo - FGV e CEQEF-FGV. E-mail: pedro.valls@ fgv.br. Os autores agradecem financiamento do CNPq e o segundo e terceiro autores agradecem também o financiamento da FAPESP. Os autores agradecem ao editor e a dois pareceristas anônimos desta revista pelos comentários e sugestões. Erros remanescentes são de responsabilidade dos autores

Rev. Bras. Finanças (Online), Rio de Janeiro, 14, No. 1, March 2016, pp. 7-4 ISSN 1679-0731, ISSN online 1984-5146

(c) 2016 Sociedade Brasileira de Finanças, under a Creative Commons Attribution 3.0 license -

http://creativecommons.org/licenses/by/3.0 
Palavras-chave: Microestrutura do mercado de câmbio; Fluxo de Ordem; Probabilidade de Transação Informativa (PIN); Mercado Futuro de Câmbio Brasileiro. Códigos JEL:G10, E43, C58

\begin{abstract}
The microstructure approach to exchange rates have received special attention in recent years, particularly because it highlights the existence of asymmetric information in this market. The Brazilian future FX market data provided from BM\&F was used to test the private information effects of trading on prices. The structural VAR results confirm the existence of asymmetric information in this market, indicating that roughly $50 \%$ of all efficient price variation is due to the private information of the order flow. Additionally, the order flow observation allows the informed and uninformed arrival rates estimation, which we use to calculate the probability of information-based trade (PIN). High PIN value leads to wide spreads, which reduces the market liquidity. The PIN results about $1.53 \%$ indicate the liquidity of Brazilian future FX market is quite high, what impound fewer trading costs for the uninformed agents
\end{abstract}

Keywords: FX Microstructure approach; Order Flow; Probability of Informationbased Trade (PIN); Brazilian future FX Market.

\title{
1. Introdução
}

Durante muitos anos, os estudos referentes ao mercado de câmbio focaram seus esforços nas variáveis macro-fundamentadas como inflação, diferencial da taxa de juros e prêmio de risco, para explicar os movimentos de preço da moeda estrangeira. Não se atribuía probabilidades de agentes terem acesso privado a algum tipo de informação relevante para a taxa de câmbio porque acreditava-se que todas estas informações eram de conhecimento público.

Assim, por muito tempo, a hipótese de assimetria de informação foi ignorada. Esta e outras características do mercado de câmbio começaram a ser analisadas somente a partir da publicação do trabalho seminal de Meese e Rogoff (1983), que apresentou um paradoxo à teoria econômica quando afirmou que a abordagem convencional do mercado de ativos, com variáveis macro-fundamentadas, não era melhor do que um passeio aleatório na explicação dos movimentos da taxa de câmbio nominal.

Este paradoxo resumiu a incapacidade que os modelos convencionais prevalecentes até meados dos anos 1980 apresentavam ao explicar empiricamente toda a variação do câmbio nominal, principalmente em freqüências maiores do que um ano. (Evans e Lyons, 2002, p.170).

As pesquisas que surgiram nos últimos anos a fim de resolver este pa- 
radoxo tiveram como destaque a abordagem da microestrutura.

Esta abordagem afirma que somente parte das informações que são relevantes para a formação da taxa de câmbio é publicamente conhecida. A outra parte está dispersa no mercado e apenas alguns agentes recebem sinais que lhes dão acesso a ela como informação privada.

A abordagem da microestrutura tem sido pouco utilizada nas pesquisas feitas sobre o mercado brasileiro de câmbio. Entre os estudos realizados, podemos destacar os trabalhos de Garcia e Urban (2004); Wu (2010); Laurini et al (2008) e Fernandes (2008).

O objetivo central do trabalho é verificar a existência de informação assimétrica na dinâmica das cotações da taxa de câmbio Real/Dólar nos contratos futuros da Bolsa de Mercadorias e Futuros brasileira (BM\&F). Ainda que trabalhos como o de Laurini et al (2008) tenham apontado para a existência de informação assimétrica no mercado brasileiro de câmbio, nenhum dos estudos calculou o impacto agregado da informação privada carrega pelas transações. Este resultado é obtido através do modelo de vetor auto-regressivo (VAR) estrutural idealizado por Hasbrouck (1991a, 1991b), que compreende a iteração dinâmica entre as transações e as cotações de ordens de compra e venda do mercado, quando o preço eficiente não é observável.

Robusto a desvios de hipóteses fortes como mercado centralizado e neutralidade do risco dos agentes, presentes nos modelos teóricos de microestrutura como Kyle (1985) e Glosten e Milgrom (1985); este modelo é caracterizado por ser flexível no sentido de não necessitar de nenhum modelo teórico de microestrutura em particular. Nele, o impacto permanente da informação privada carregada pelas transações ao mercado é perfeitamente mensurado pelo efeito das inovações do fluxo de ordem sobre as cotações da moeda estrangeira. Esta é uma outra contribuição deste trabalho em relação ao trabalho de Wu (2010) que usa dados do Sisbacen. Esta base contém todas as transações consolidadas de câmbio do Brasil, não fornece, no entanto, a verdadeira informação que os agentes de mercado dispõem quando tomam suas decisões. Isto porque muitas vezes não estão publicamente disponíveis, e quando estão, apresentam atraso de publicação inviabilizando qualquer tomada de decisão sobre eles.

Para identificar as transações informativas, o modelo fará uso das funções de impulso resposta do fluxo de ordem sobre os preços. Os fluxos de ordem informativos são entendidos como aqueles que induzem uma resposta de longo prazo diferente de zero nos preços. Os resultados indicam que 
o acúmulo de inovações positivas do fluxo de ordem, ou seja, o acúmulo de compras inesperada de 1,000 dólares no mercado aumenta o retorno das cotações em 0.1 pontos percentuais. Além disso, a decomposição da variância do preço eficiente, também proposta por Hasbrouck (1991a), permite calcular uma medida relativa do conteúdo informacional das transações, denominada Information Share (IS). As estimativas sugerem que aproximadamente $50 \%$ da variação do componente permanente dos preços é atribuída à informação privada, indicando a existência de assimetria de informação neste mercado.

Visto que a proporção da informação privada que afeta os movimentos dos preços é relativamente alta, uma extensão da análise sobre os determinantes da dinâmica conjunta entre preços e transações se faz necessária. A análise da probabilidade de ocorrência de transações baseadas em informação $(\mathrm{PIN})^{1}$ gera uma medida de liquidez do mercado e permite que os gestores de portfólios possam tomar suas decisões de maneira mais assertiva.

O modelo de Easley et al (1996), baseado no trabalho teórico de Easley e O'Hara $(1987,1992)$ e na estrutura informacional de Glosten e Milgrom (1985), faz uso da função de verossimilhança para prever as taxas de chegada de ordens de agentes informados e não informados a partir da observação do fluxo de ordem. Os resultados da estimação da função de verossimilhança mostraram que a cada dia, 3.078 agentes não informados chegam ao mercado enquanto que a proporção de agentes informados é bem menor, apenas de $7 \%$ desta taxa. Por tratar-se de um mercado muito líquido e que envolve volumes grandes de negócios, a probabilidade da primeira transação do dia ser informativa (PIN) é baixa, e se aproxima de $1,53 \%$, mesmo considerando um mercado onde a informação privada é responsável por $50 \%$ da variação do componente permanente dos preços.

Após esta introdução, a segunda seção apresenta uma análise da abordagem da microestrutura para a taxa de câmbio. Na terceira seção, a estratégia empírica é delineada, descrevendo a metodologia utilizada no trabalho. Em seguida, a quarta seção descreve a base de dados e a quinta, formaliza os modelos VAR estrutural e PIN para obter os resultados propostos. Por fim, a sexta seção discute as conclusões do trabalho.

\footnotetext{
${ }^{1}$ Do inglês Probability of Informed Trades
} 


\section{MODELOS PARA TAXA DE CÂMBIO}

\subsection{Modelos Prevalecentes até Meados de 1980}

A análise da microestrutura de mercado como uma abordagem alternativa de modelos que fossem capazes de explicar as variações da taxa de câmbio mundiais começou como resposta ao paradoxo apresentado por Meese e Rogoff (1983). Os autores afirmaram que os modelos macrofundamentados não explicavam melhor as variações da taxa de câmbio do que um passeio aleatório simples.

A abordagem que prevalecia antes da década de 1970 ficou conhecida como a abordagem do mercado de bens, e está fundamentada na hipótese de Paridade do Poder de Compra (PPP) ${ }^{2}$. Nela, a demanda por moeda estrangeira era determinada essencialmente pelos fluxos da balança comercial, de modo que o país que experimentasse um superávit comercial teria uma apreciação de sua moeda local. Segundo afirmavam Frenkel (1976) e Dornbusch (1976), a taxa de câmbio era a razão entre os níveis de preços de dois países e, portanto, as mudanças da taxa de câmbio se davam via alterações nos preços relativos. As análises empíricas, entretanto, não conseguiram comprovar satisfatoriamente a existência de uma correlação entre os movimentos do câmbio e a balança comercial de grande parte dos países. Os trabalhos desta análise empírica podem ser encontrados em Meredith e Chinn (1998) e Abuaf e Jorion (1990).

Na década de 1970 surgiram modelos que incorporavam - além da comercialização de bens - os fluxos financeiros como determinantes da taxa de câmbio, a fim de relacionar os movimentos da moeda local com as oportunidades de investimento dos agentes estrangeiros. Esta ficou conhecida como a abordagem do mercado de ativos, na qual o preço é determinado pela expectativa de renda que pode ser obtida com a propriedade de ativos de um determinado mercado de câmbio. Seus modelos estão baseados fundamentalmente em cinco hipóteses: (i) homogeneidade dos agentes; (ii) expectativas racionais; (iii) informação simétrica; (iv) estruturas com agente representativo; e (v) ausência de custos de transação.

Esses modelos eram caracterizados por terem como principais determinantes das variações da taxa de câmbio nominal $\left(\Delta P_{t}\right)$ o diferencial de juros nominal $\left(i-i^{*}\right)$, a oferta de moeda $(m)$ e outras variáveis macroeconômicas $(z)$, de forma a serem caracterizados pela seguinte expressão:

\footnotetext{
${ }^{2}$ De acordo com a PPP, uma determinada moeda deve ter o mesmo poder aquisitivo, em termos internacionais, em qualquer país.
} 


$$
\Delta P_{t}=f\left(i-i^{*}, m, z\right)+\varepsilon_{t}
$$

onde $\varepsilon_{t}$ representa o termo de erro com média zero e variância $\sigma_{\varepsilon}^{2}$. Neles, o papel dos negócios era nulo porque acreditava-se que todas as informações macroeconômicas que afetavam $\Delta P_{t}$ eram publicamente anunciadas. Assim, qualquer possível efeito das transações sobre os preços estava inserido no termo de erro aleatório $\varepsilon_{t}$.

Mesmo tendo incorporado toda a informação pública disponível no mercado em determinado período de tempo, estes modelos, quando testados empiricamente, não sustentaram a idéia de que apenas as variáveis macroeconômicas eram capazes de afetar a taxa de câmbio nominal. De acordo com Taylor (1995), os fundamentos macroeconômicos são claramente muito importantes para determinar os parâmetros que influenciam os movimentos de curto prazo dos preço da moeda estrangeira, mas não conseguem comprovar sozinhos todos estes movimentos. Trabalhos como os de Taylor (1995), Frankel e Rose (1995) e Flood e Taylor (1996) expõem uma extensa análise empírica de como os modelos macro-convencionais não foram efetivos na explicação da evolução dos preços da moeda estrangeira. Neste sentido, surgiu a necessidade de encontrar modelos que pudessem capturar algumas características inerentes ao mercado cambial como, por exemplo, o alto volume de negociações diárias deste mercado.

\subsection{Modelos de Microestrutura para a Taxa de Câmbio}

Como alternativa aos modelos econômicos convencionais, surgiu a abordagem da microestrutura aplicada ao mercado de câmbio. Nela, as restrições teóricas não são tão fortes, de modo a permitir que características inerentes do mercado de câmbio - como descentralização e distância física entre os operadores - sejam levadas em consideração. Assim, o conjunto de informação deixa de ser igual para todos os agentes, e a informação privada passa a ser relevante no processo de determinação dos preços.

Em suma, os modelos de microestrutura de mercado flexibilizam três das hipóteses fundamentais citadas acima: (i) as informações relevantes para a determinação da taxa de câmbio não estão publicamente disponíveis; (ii) os agentes não são homogêneos; e (iii) os mecanismos de transação também diferem entre si, fazendo com que as instituições sejam diferentes ${ }^{3}$.

\footnotetext{
${ }^{3}$ Existem mercados que são híbridos, ou seja, que aceitam ordens limite e que têm também provedores de liquidez (market-makers). O fato de as transações ocorrerem por esses dois mecanismos diferentes faz com que os preços sejam afetados de forma diferente.
} 
Estes modelos adicionam à equação (1) a importância da assimetria de informação na formação dos preços, de forma que sua generalização possa ser dada pela expressão da variação do valor fundamental da moeda estrangeira $\left(\bar{P}_{t}\right)$ :

$$
\Delta \bar{P}_{t}=\alpha \Delta M_{t}+\beta \varepsilon_{2, t}+\varepsilon_{1, t}
$$

onde $\Delta M_{t}$ representa as variações dos fundamentos macroeconômicos de informação pública, $\varepsilon_{1, t}$ representa os choques de informação pública, e o coeficiente $\beta$ captura a quantidade de informação que é transmitida ao mercado através da informação privada sobre os fundamentos, $\left(\varepsilon_{2, t}\right)$. Ou seja, os modelos de microestrutura passam a mensurar o efeito do conteúdo informacional privado sobre os preços que antes estavam inseridos no termo de erro aleatório.

As flexibilizações acima permitiram a existência de dois tipos de agentes no mercado: aqueles que têm informação superior sobre os fundamentos da taxa de câmbio e que transacionam para lucrar com esta vantagem informacional; e aqueles que não recebem estes sinais de informação privada e transacionam basicamente por liquidez a partir de informações públicas disponíveis. A implicação direta disto, segundo os modelos teóricos de Glosten e Milgrom (1985) e Easley e O'Hara (1987), é a existência de um componente de custo de informação assimétrica no spread entre ofertas de compra e venda (bid e ask).

Como o agente que tiver uma informação privada sobre algum fundamento irá utilizá-la para extrair vantagens lucrativas, ele certamente irá iniciar uma transação de acordo com a informação que recebeu, executando as ordens pré-estabelecidas no mercado, ao invés de postá-las. Portanto, o conhecimento de quem inicia uma transação - se um comprador ou um vendedor - é de fundamental importância para a análise do impacto que as informações assimétricas têm sobre o movimento dos preços. A noção de que as transações carregam informações ao mercado fez surgir a idéia de fluxo de ordem, que se caracterizou por ser uma das principais contribuições das análises da microestrutura de mercado.

O fluxo de ordem revela a diferença líquida das ordens iniciadas por compradores em relação àquelas iniciadas pelos vendedores (Evans e Lyons, 2002, p.171). Distinto do volume das transações por um sinal, ele indica o lado iniciante de uma negociação. A convenção é de que se a transação é iniciada por um vendedor (comprador), o fluxo de ordem tem sinal negativo (positivo). Portanto, o componente de informação privada $\left(\varepsilon_{2, t}\right)$ da equação 
(2) passa a representar as inovações do fluxo de ordem. No mercado de câmbio, em particular, os trabalhos de Rime (2001) e Evans e Lyons (2001) mostram que o fluxo de ordem apresenta efeitos significativos e persistentes sobre as taxas de câmbio.

Um exemplo de um sinal privado sobre os fundamentos da taxa de câmbio pode ser visto no setor de exportação brasileiro. Pela legislação vigente no país, uma empresa exportadora deve entregar as divisas que obtém com seus negócios a alguma instituição financeira autorizada pelo Banco Central, convertendo-as em moeda nacional. Como a exportação é um fundamento macroeconômico, deveria ter impacto sobre a cotação de câmbio imediatamente. Entretanto, no momento da negociação, esta informação não é de conhecimento público. Pelo contrário, é uma informação privada que a empresa exportadora e a instituição na qual as divisas são depositadas possuem. Ao transacionar os dólares no mercado de câmbio, o fluxo de ordem desta instituição, originada a partir do fundamento, estará refletindo sua informação privada ao mercado.

\subsection{Modelo de Microestrutura de Glosten}

Supondo que $m_{t}$ seja o preço eficiente de determinado ativo, ou seja, a expectativa do valor verdadeiro do ativo condicional em toda a informação necessária para sua valoração, então a expressão que o determina é dada por:

$$
m_{t}=m_{t-1}+z v_{2, t}+v_{1, t}
$$

onde $v_{1, t}$ representa a informação pública (que não vem das transações) e $v_{2, t}$, o componente inesperado das transações. Portanto, $z v_{2, t}$ é a resposta do preço eficiente às inovações das transações, e $z$ é o coeficiente que reflete a informação assimétrica. Esta equação está muito próxima do modelo geral apresentado na equação (2).

Como veremos a seguir, os agentes de mercado formam ordens de compra e venda de tal sorte que a cotação média entre elas reflete exatamente suas expectativas em relação ao valor futuro da taxa de câmbio, cuja evolução pode ser dada por:

$$
q_{t}=m_{t}+a\left(q_{t-1}-m_{t-1}\right)=b x_{t}
$$

com $q_{t}=\frac{p_{t}^{c}+p_{t}^{v}}{2}$, onde $p_{t}^{c}$ e $p_{t}^{v}$ representam as cotações da ordem de compra e venda, respectivamente, $x_{t}$ representa o fluxo de ordem, e os 
parâmetros $a$ e $b$ representam os coeficientes de ajustamento, com $0<a \leq$ 1 e $b>0$.

A principal contribuição do modelo é a inclusão da dinâmica do fluxo de ordem, que não apenas depende dos desvios da cotação média em relação ao preço fundamental, mas está diretamente relacionado com a informação privada contida nas suas inovações $v_{2, t}$ :

$$
x_{t}=-c\left(q_{t-1}-m_{t-1}\right)+v_{2, t}
$$

Do ponto de vista econométrico, entretanto, estas equações não são válidas uma vez que o preço eficiente $m_{t}$ não pode ser observado. Para que as estimativas destas equações possam ser obtidas, é necessário rearranjar as equações (4) e (5) de forma que tudo fique em função das variáveis observáveis no mercado $x_{t}$ e $q_{t}$. Seja $r_{t}=q_{t}-q_{t-1}$ o retorno das cotações médias, então:

$$
\begin{gathered}
r_{t}=(z+b) x_{t}+[z b c-(1-a)] x_{t-1}+a[z b c-(1-a) b] x_{t-2}+\ldots+v_{1, t} \\
x_{t}=-b c x_{t-1}-a b c x_{t-2}-a^{2} b c x_{t-3}+\ldots+v_{2, t}
\end{gathered}
$$

Como podemos perceber, estes parâmetros são funções complicadas e não-lineares dos parâmetros originais. O modelo VAR estrutural apresentado por Hasbrouck (1991a, 1991b) facilita esta análise por trabalhar com parâmetros lineares num sistema que mantém a hipótese de que o impacto das transações nos preços não é imediato. Ou seja, este modelo não assume que o fluxo de ordem é dado exogenamente e permite que haja feedback dos preços sobre as transações.

Aplicado ao mercado de ativos por De Jong, Nijman e Röel (1995) e Hamao e Hasbrouck (1995), e ao mercado de câmbio dólar/marco alemão por Payne (1999), este modelo é robusto a desvios das hipóteses dos modelos teóricos de microestrutura. Ou seja, nele não há necessidade de impor restrições fortes como a hipótese de mercado centralizado ou a hipótese de neutralidade do risco dos agentes utilizadas por modelos de informação como Kyle (1985) e Glosten e Milgrom (1985). E por ser robusto a estes desvios, o modelo se caracteriza por ser flexível, no sentido de não necessitar nenhum modelo teórico particular.

Como veremos a seguir, o modelo VAR permite identificar as transações informativas através das funções de impulso resposta, e permite construir 
uma medida relativa de informação assimétrica através da inferência a importância da informação privada sobre o total de informação que afeta os preços. Esta medida é obtida através da decomposição da variância do preço eficiente.

\section{Metodologia Empírica}

\subsection{Modelo de Autorregressivo Vetorial Estrutural (SVAR)}

O modelo a seguir está baseado na convenção de que os agentes de mercado registram as ordens de compra e venda que estão dispostos a negociar. Uma transação é caracterizada pelo fluxo de ordem $\left(x_{t}\right)$, que é positivo se a transação for iniciada por ordem de compra e negativo se iniciada por ordem de venda ${ }^{4}$. As cotações que prevalecem antes da transação $x_{t}$ são denominadas por $p_{t-1}^{c}$ e $p_{t-1}^{v}$ e as revisões subseqüentes em $p_{t}^{c}$ e $p_{t}^{v}$ refletem as informações sobre a observação de $x_{t}$.

Supondo novamente que $m_{\tau}$ seja o preço verdadeiro da moeda estrangeira (valor condicional na informação total dos fundamentos - quando os agentes têm acesso a todas as informações privadas), pela decomposição do spread feita por Glosten (1987), temos que o preço verdadeiro baseado na informação pública $\Phi_{t}$ é dado por:

$$
m_{t}^{*}=E\left[m_{\tau} \mid \Phi_{t}\right]
$$

Se assumirmos que todos os potenciais agentes de mercado possuem apenas o conhecimento público $\Phi_{t}$, então as revisões em $p_{t}^{c}$ e $p_{t}^{v}$ feitas após o anúncio de uma transação podem ser dadas por:

$$
\begin{gathered}
a\left(p_{t}^{v}\right)=E\left[m_{\tau} \mid \Phi_{t}, \text { "investidores compraram ao preço } p_{t-1}^{v} "\right] \\
b\left(p_{t}^{c}\right)=E\left[m_{\tau} \mid \Phi_{t}, " \text { investidores venderam ao preço } p_{t-1}^{c} "\right]
\end{gathered}
$$

onde as funções $a($.$) e b($.$) descrevem a forma como as expectativas$ condicionais na informação pública disponível no mercado são atualizadas em resposta às transações realizadas sobre diversos preços de ordens

\footnotetext{
${ }^{4} \mathrm{O}$ fluxo de ordem será positivo se um agente, após analisar as ordens prevalecentes no mercado, decide postar uma ordem de compra para que uma transação seja realizada sobre uma ordem de venda. O mesmo raciocínio vale para o fluxo de ordem negativo.
} 
de compra e venda $p_{t}^{c}$ e $p_{t}^{v}$. Portanto, estas são as atualizações feitas no conjunto de informação pública a cada transação realizada no mercado

$\mathrm{Na}$ abordagem da microestrutura, além do fluxo de ordem representando as características das transações e, portanto, representando a quantidade; é comum utilizar o spread entre as ofertas de compra e venda (bid e ask) como variável observável de preço. Relacionado com a liquidez dos ativos, o spread representa o excesso de preço requerido em relação ao preço mais alto que os agentes estão dispostos a pagar. Sua existência se deve aos desvios dos preços transacionados do seu nível de equilíbrio, que geram custos de transação compostos pelos custos de seleção adversa, custos de inventário e custos fixos.

Assim, o tamanho do spread captura também outros custos de transação que não somente os custos relacionados com a assimetria de informação do mercado, quais sejam custos de seleção adversa. Tais custos foram inicialmente analisados por Glosten e Milgrom (1985), quando afirmaram existir dois tipos de participantes no mercado: aqueles informados e aqueles que não recebem sinais de informação. Segundo os autores, ambos os tipos não conseguem distinguir se a sua contraparte na negociação é um agente mais bem informado que ele próprio ou não. Isto faz com que todos os agentes anunciem cotações que tornam o spread amplo o suficiente para que suas perdas de negócios feitos com agentes mais bem informados sejam compensadas pelos ganhos obtidos com transações realizadas com os menos informados.

Portanto, ao invés do spread, o presente trabalho faz uso da cotação média entre as melhores ofertas de compra e venda como variável de preço. Sua utilização está baseada na hipótese dada por Hasbrouck (1991b) e por Easley et al (1996) de que as cotações são dadas de forma simétrica em relação à expectativa da cotação de câmbio futura condicional em toda informação pública. Ou seja,

$$
E\left[\frac{p_{t}^{c}+p_{t}^{v}}{2}-m_{\tau} \mid \Phi_{t}\right]=\frac{p_{t}^{c}+p_{t}^{v}}{2}-E\left[m_{\tau} \mid \Phi_{t}\right]=0
$$

onde $m_{\tau}$ representa o valor da taxa de câmbio no instante futuro $\tau, \Phi_{t}$ representa o conjunto de informação pública disponível no tempo $t$ (incluindo as cotações e as transações em $t$ ), e $p_{t}^{c}$ e $p_{t}^{v}$ representam as melhores ofertas de compra e venda do mercado, respectivamente.

Como visto acima, a informação referente à transação no período $t$, pode ser observada na revisão subseqüente da cotação média $\bar{r}_{t}$ : 


$$
\bar{r}_{t}=\frac{p_{t}^{* c}+p_{t}^{* v}}{2}-\frac{p_{t-1}^{* c}+p_{t-1}^{* v}}{2}
$$

Mas se atentarmos para o fato de que quando o topo do book de compras possui um volume maior de ordens do que o de vendas há, no mercado, mais agentes acreditando que a cotação irá subir (ou no caso de apenas uma ordem grande de compra, existe um investidor com uma crença muito forte de que a cotação irá subir num futuro próximo), então podemos afirmar que o volume do topo do book apresenta uma importante informação sobre as expectativas dos agentes do mercado.

Neste sentido, o presente trabalho propõe a substituição da média simples pela média ponderada pela quantidade ofertada do lado oposto do book como variável de preço, uma vez que esta revela com maior precisão para que lado a cotação está mais propensa a variar devido ao acúmulo de quantidades do book de ofertas. Denominando $p_{t}$ como a média ponderada proposta, temos:

$$
p_{t}=\frac{p_{t}^{* c} q_{t}^{* v}+p_{t}^{* v} q_{t}^{* c}}{q_{t}^{* c}+q_{t}^{* v}}
$$

onde $q_{t}^{* c}$ e $q_{t}^{* v}$, representam as quantidades das ordens de compra e venda do topo do book, respectivamente.

Como o preço eficiente define-se como sendo a expectativa dos agentes sobre o valor futuro da cotação de câmbio condicional na informação pública disponível ${ }^{5}$, então a média ponderada $\left(p_{t}\right)$ está mais próxima do preço eficiente do que a média simples aritmética, cujas vantagens podem ser vistas no Gráfico 1. Podemos perceber que a média ponderada sinaliza de forma antecipada a tendência de preço a ser negociado nas próximas transações ${ }^{6}$.

O sistema que permite a iteração dinâmica do fluxo de ordem com a variável de preço $r_{t}=\ln \left(p_{t}\right)-\ln \left(p_{t-1}\right)$ é o modelo de autorregressivo vetorial estrutural (SVAR) dado por:

$$
r_{t}=\sum_{i=1}^{p} \alpha_{i} r_{t-i}+\sum_{i=0}^{p} \beta_{i} x_{t-i}+\varepsilon_{1, t}
$$

\footnotetext{
${ }^{5}$ Parece pouco intuitivo que o preço eficiente seja muito diferente do preço de negociação, pois se este foi o caso teriamos ineficiências constantes no mercado o que parece não ser o caso.

${ }^{6}$ Embora seja apresentado somente um dia este resultado é sistemático em outros dias.
} 


\section{Figura 1}

Comparação entre cotações médias - simples e ponderada, 01/08/2011.

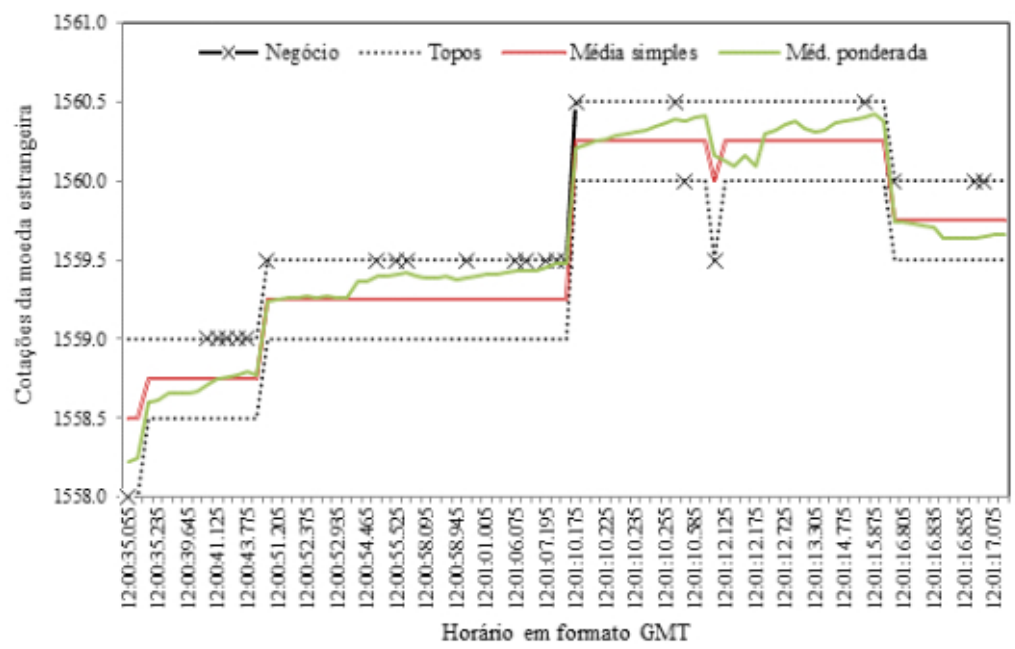

$$
x_{t}=\sum_{i=1}^{p} \gamma_{i} r_{t-i}+\sum_{i=1}^{p} \delta_{i} x_{t-i}+\varepsilon_{2, t}
$$

que para fins de identificação requer as seguintes restrições sobre as inovações:

$$
\begin{gathered}
E\left(\varepsilon_{1, t}\right)=E\left(\varepsilon_{2, t}\right)=E\left(\varepsilon_{1, t} \varepsilon_{2, t}\right)=0 \\
E\left(\varepsilon_{1, t}^{2}\right)=\sigma_{\varepsilon_{1}}^{2} \text { e } E\left(\varepsilon_{2, t}^{2}\right)=\sigma_{\varepsilon_{2}}^{2} \\
E\left(\varepsilon_{1, t} \varepsilon_{2, s}\right)=E\left(\varepsilon_{1, t} \varepsilon_{1, s}\right)=E\left(\varepsilon_{2, t} \varepsilon_{2, s}\right)=0, \forall t \neq s
\end{gathered}
$$

Uma das vantagens deste modelo é a inclusão da dinâmica do fluxo de ordem dada pela equação (15), e ignorada em outros modelos de microestrutura. Assume-se que existe um impacto defasado dos retornos sobre as decisões de negociações e que as transações possuem algum tipo de correlação, no sentido de que compras devem seguir compras do mesmo modo que vendas devem seguir vendas. É importante notar que as imperfeições da microestrutura, como a discretização do preço, impõem efeitos de defasagens também na equação (14), uma vez que as revisões nas cotações 
podem não ser ótimas até várias transações na mesma direção terem ocorrido $^{7}$.

O parâmetro $\beta_{0}$ da equação (14) mede o impacto contemporâneo (imediato) das transações no nível de preços. A inclusão deste termo garante que a estrutura recursiva da matriz de relações contemporâneas das variáveis, requerida pela decomposição de Cholesky, seja atendida ${ }^{8}$. Desta forma, podemos dizer que o modelo está bem especificado e pode ser consistentemente estimado.

A ordenação causal das transações para os preços é uma hipótese econômica feita ad hoc (embora a nota de pé de página 8 apresente uma justificativa econométrica para esta ordenação), com base na observação do comportamento das operações no book de ofertas. Sempre que há uma transação no mercado, o topo do book de compras, ou o topo do book de vendas, ou ambos, são atualizados; e o contrário não é verificado ${ }^{9}$.

Além disso, o modelo requer outra hipótese econômica igualmente importante:

A informação pública é imediatamente refletida nos preços. Caso contrário, os agentes poderiam sempre montar estratégias lucrativas através de suas observações, de modo que a informação pública e as transações fossem correlacionadas. Esta é conhecida como a hipótese de que o mercado é eficiente de forma semi-forte ${ }^{10}$.

As inovações da equação (14) representam os efeitos da informação pública, enquanto que as inovações da equação das transações $\left(\varepsilon_{2, t}\right)$ representam a informação privada que o fluxo de ordem traz ao mercado. Esta última afirmação pode ser melhor entendida com a análise da equação (15). Com base na história das transações e dos retornos, os agentes formam expectativas sobre a t-ésima transação, de modo que qualquer atividade não esperada das negociações é refletida em $\varepsilon_{2, t}$. Dessa forma, $\varepsilon_{2, t}$ representa

\footnotetext{
${ }^{7}$ Ver Harris (1990).

${ }^{8}$ A não correlação dos erros nas duas equações dada em (16) garante que $x_{t}$ é exógeno fraco para os parâmetros do modelo condicional, equação (14). Isto valida a estimação por MQO do modelo (14-15). Por um lado, não temos o porblema de identificação neste caso uma vez que as condições de identificação de modelos de equações simultâneas estão sendo satisfeitas neste caso. E por outro lado dada a estrutura triangular temos uma relação de precedência de $x_{t}$ para $r_{t}$, implicando em causalidade no sentido de Granger de $x_{t}$ para $r_{t}$.

${ }^{9} \mathrm{O}$ teste de causalidade de Granger entre as variáveis, nesses casos, não é condição necessária e nem suficiente para a ausência (ou presença) de efeito contemporâneo de uma variável para outra. Ou seja, os resultados do referido teste não servem para fins de identificação do VAR como muitos estudos afirmam. (Cavalcanti, 2010, pp. 253)

${ }^{10}$ Semi-strong-form efficient market
} 
a possibilidade das transações terem ocorrido a partir de informações privilegiadas.

Podemos reescrever o modelo SVAR descrito acima na seguinte representação matricial:

$$
\left(\begin{array}{cc}
1 & -\beta_{0} \\
0 & 1
\end{array}\right)\left(\begin{array}{l}
r_{t} \\
x_{t}
\end{array}\right)=\left(\begin{array}{cc}
\alpha(L) & \beta(L) \\
\gamma(L) & \delta(L)
\end{array}\right)\left(\begin{array}{c}
r_{t} \\
x_{t}
\end{array}\right)+\left(\begin{array}{c}
\varepsilon_{1, t} \\
\varepsilon_{2, t}
\end{array}\right)
$$

onde os coeficientes da primeira matriz do lado direito representam os polinômios do operador de defasagem, e

$$
\operatorname{Var}\left(\begin{array}{c}
\varepsilon_{1, t} \\
\varepsilon_{2, t}
\end{array}\right)=\left(\begin{array}{cc}
\sigma_{\varepsilon_{1}}^{2} & 0 \\
0 & \sigma_{\varepsilon_{2}}^{2}
\end{array}\right)
$$

Supondo invertibilidade da matriz

$$
\left(\begin{array}{cc}
1-\alpha(L) & -\beta_{0}-\beta(L) \\
-\gamma(L) & 1-\delta(L)
\end{array}\right)
$$

as transações e a revisão das cotações podem ser expressas como funções lineares das inovações correntes e passadas, através da representação do vetor de médias móveis (VMA):

$$
\left(\begin{array}{c}
r_{t} \\
x_{t}
\end{array}\right)=\left(\begin{array}{cc}
a(L) & b(L) \\
c(L) & d(L)
\end{array}\right)\left(\begin{array}{l}
\varepsilon_{1, t} \\
\varepsilon_{2, t}
\end{array}\right)
$$

Os polinômios de defasagem desta representação são as funções de impulso resposta da representação VAR estrutural descrita acima. Dentre todos, $b(L)$ é o polinômio de defasagem mais importante, pois captura os efeitos da informação privada sobre os preços subseqüentes. O coeficiente $b_{k}$ revela o efeito de uma unidade de inovação do fluxo de ordem sobre variação percentual da média das cotações $\left(r_{t}\right)$ num horizonte de $k$ períodos.

Ou seja, a partir desta representação é possível identificar a medida de informação das transações sobre os preços. A soma dos efeitos da informação privada ao longo de todos os períodos fornece uma medida do impacto cumulativo e persistente do fluxo de ordem sobre os níveis de preços, através da mudança dos retornos. Portanto, $\sum_{k=0}^{\infty} b_{k}$ representa o conteúdo informacional do fluxo de ordem. Mas para entender a importância da informação do fluxo de ordem é necessário conhecer também a sua participação na variância total. 


\subsection{Decomposição da Variância do Preço Eficiente}

O pressuposto de que os preços de diversos mercados compartilham um mesmo preço eficiente implícito foi defendido primeiramente por Garbade e Silber (1982). Hasbrouck (1991a, 1995), seguindo a mesma idéia, assume que o preço singular observado de um ativo também possui preço implicitamente eficiente, atribuindo às transações e às ordens de compra e venda a origem das variações desse preço. O preço eficiente é interpretado aqui como o valor que a taxa de câmbio assume quando todos os fundamentos necessários para sua valoração são conhecidos por todo o mercado. Como este é um caso improvável, entende-se que a cotação da taxa de câmbio será próxima deste preço eficiente, porém perturbada por ruídos de informação assimétrica.

Tendo em vista o trabalho de Hasbrouck (1991a), assim como a maioria dos modelos de microestrutura, assume-se neste trabalho as cotações da taxa de câmbio são determinadas pela soma de dois componentes não observáveis: um referente ao preço eficiente, $m_{t}$, que segue um passeio aleatório, e outro componente transitório e estacionário, $s_{t}$, tal que:

$$
p_{t}=m_{t}+s_{t}
$$

onde $p_{t}=\frac{p_{t}^{* c} q_{t}^{* v}+p_{t}^{* v} q_{t}^{* c}}{q_{t}^{* c}+q_{t}^{* *}}, m_{t}=m_{t-1}+w_{t}$ e $w_{t} \sim N\left(0, \sigma_{w}^{2}\right)$, com $E\left(w_{t} w_{s}\right)=0$ para $t \neq s$.

O termo transitório $s_{t}$ incorpora todas as imperfeições da microestrutura responsáveis pelos desvios da cotação central das ordens de compra e venda em relação ao preço eficiente. A variância do componente permanente $m_{t}$, dada pelo parâmetro $\sigma_{w}^{2}$, pode ser estimada igualando-se a equação (23) e a equação da revisão das cotações da representação VMA em (22):

$$
\sigma_{w}^{2}=\left(\sum_{k=0}^{\infty} a_{k}\right)^{2} \sigma_{\varepsilon_{1}}^{2}+\left(\sum_{k=0}^{\infty} b_{k}\right)^{2} \sigma_{\varepsilon_{2}}^{2}
$$

Assim, as mudanças no preço eficiente podem ser divididas em dois componentes: um relacionado com as transações (referente à informação do fluxo de ordem) e outro que não tem relação com elas (referente à informação pública). Esta decomposição da variância leva a uma medida absoluta e outra relativa do grau informativo de uma transação. A medida absoluta dada pela variação das inovações do fluxo de ordem pode ser expressa por: 


$$
\sigma_{x}^{2}=\left(\sum_{k=0}^{\infty} b_{k}\right)^{2} \sigma_{\varepsilon_{2}}^{2}
$$

E a contribuição relativa da informação transmitida aos preços através do fluxo de ordem indica a importância das transações para a movimentação dos preços. Hasbrouck (1995) denominou esta importância relativa por Information Share (IS), definida por:

$$
I S=\frac{\sigma_{x}^{2}}{\sigma_{w}^{2}}
$$

O modelo VAR estrutural das equações (14) e (15) é consistentemente estimado por mínimos quadrados ordinários quando a hipótese de estacionariedade conjunta das variáveis $r_{t}$ e $x_{t}$ for válida. Os resultados são reportados com desvios padrões robustos à heteroscedasticidade. A invertibilidade da matriz (21) possibilita a recuperação dos coeficientes da representação VMA, feita por simulação ${ }^{11}$. Ainda, a obtenção das funções de impulso resposta permite que a decomposição da variância gere estimativas para $\sigma_{w}^{2}$ e $\sigma_{x}^{2}$.

\subsection{Modelo para o Cálculo da Probabilidade das Transações serem Informativas (PIN)}

A medida relativa da importância da informação privada na variação dos preços da moeda estrangeira, entretanto, não auxilia os gestores de carteiras de câmbio a tomarem suas decisões de forma mais correta. Pra isso, é necessária uma extensão da análise da dinâmica entre quantidade e preços. A estimação da probabilidade de ocorrência de transações baseadas em informação (PIN) gera uma medida de liquidez do mercado e permite que os gestores de portfólios tenham acesso às estimativas das taxas de chegada de ordens não observadas a partir do número de compras e vendas observado em cada dia - mesmo que eles não tenham informação de qual o tipo de agente que está por trás de cada ordem e qual o agente específico que envia determinada ordem.

Este trabalho segue o modelo de Easley et al (1996) - baseado no trabalho teórico de Easley e O’Hara $(1987,1992)$ e na estrutura informacional

\footnotetext{
${ }^{11} \mathrm{O}$ procedimento de simulação para o cálculo da representação VMA pode ser encontrado em Hamilton (1994, pp. 318).
} 
do processo de transação idealizada por Glosten e Milgrom (1985) - para modelar um mercado competitivo que contemple tanto agentes informados como agentes não informados, cujos motivos de transação diferem entre si. Nele, as transações ocorrem em dias discretos, indexados por $i=1, \ldots, I$. Em cada dia, as transações são registradas a todo o momento com diferença de registro de milésimos de segundos e ocorrem em tempo contínuo, indexado por $t \in[0, T]$. Antes que cada dia (de negociação) se inicie, a natureza escolhe se ele terá um evento informativo ou não. Estes eventos têm distribuição independente e ocorrem com probabilidade $\alpha$. Uma vez que tenham ocorrido, eles podem ser más notícias com probabilidade $\delta$, ou boas notícias com probabilidade $1-\delta$. A competição do mercado faz com que as cotações das ordens de compra e venda se igualem ao valor esperado da moeda estrangeira condicional na informação pública disponível em determinado período.

Se um agente informado observa um bom sinal (notícias boas), então a transação que maximiza seus lucros é a compra do ativo; e o contrário vale para os sinais ruins. Portanto, assume-se que agentes informados sobre as más notícias vendem o ativo e aqueles informados sobre as boas notícias compram. Assume-se também que as ordens vindas de agentes informados seguem um processo de Poisson com taxa diária de chegada $\mu$. Os agentes não informados transacionam por razões de liquidez, cujas ordens postadas no mercado também seguem um processo de Poisson, com taxa de chegada $\varepsilon .^{12}$

Portanto, a estrutura informacional idealizada por Glosten e Milgrom (1985) segue o diagrama da Figura 1. O primeiro nó representa a escolha que a natureza faz antes do início de cada dia. Se ela escolher por um evento informativo, então a natureza determina se este trará boas ou más notícias ao mercado. Nos dias em que há eventos informativos, e as notícias são boas, os agentes informados irão comprar e os agentes não informados irão comprar e vender. Portanto, a taxa de chegada de ordens de compra será de $\varepsilon+\mu$, e a taxa de chegada de ordens de venda será de $\varepsilon$. De forma análoga, nos dias em que há evento informativo, mas as notícias são ruins, os agentes informados irão vender e os agentes não informados irão vender e comprar, de maneira que a taxa de chegada de ordens de compra passa a ser $\varepsilon$, e a taxa de chegada de ordem de compra $\varepsilon+\mu$. Nos dias em que não há eventos informativos, somente os agentes não informados chegam

\footnotetext{
${ }^{12}$ Assume-se que a taxa de chegada de ordens de compras e vendas de agentes não informados são iguais.
} 
no mercado e a taxa de chegada de ordens de compra e venda são

Figura 2

Estrutura Informacional do Processo de Transação Fonte: elaboração própria baseada na estrutura de Easley et al (1996) e Glosten e Milgrom (1985)

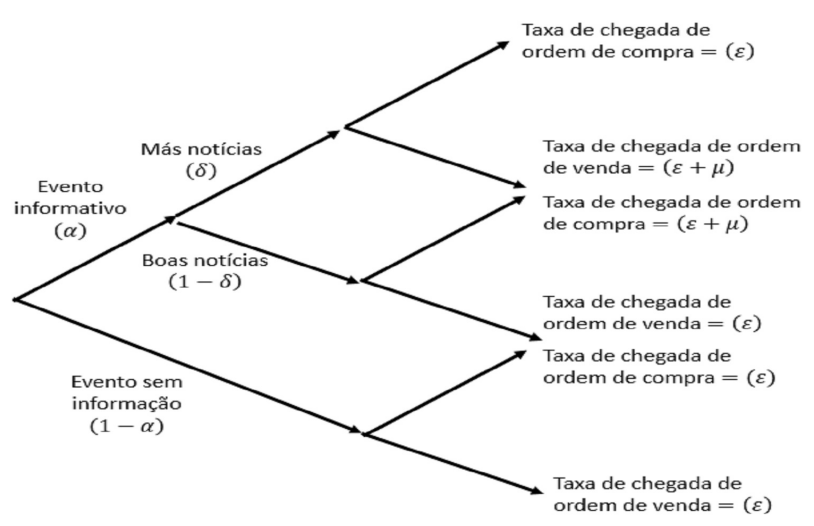

\subsubsection{Spread entre Cotações de Compra e Venda}

Para obtermos a probabilidade de uma transação ser informativa devemos caracterizar o spread entre as cotações de compra e venda a partir dessas taxas. Como os agentes não sabem qual dos nós da Figura 1 a natureza selecionou, assume-se aqui, como em Easley et al (1996) e em Easley et al (2008), que eles sejam Bayesianos e utilizam as informações sobre a realização das transações para atualizar suas expectativas em relação a ocorrência de eventos informativos. Assim, as probabilidades de boa e má informação condicionais na ordem de venda podem ser expressas, respectivamente, por:

$\operatorname{Pr}[$ boa $\mid$ venda $]=\frac{\operatorname{Pr}[\text { boa }] \varepsilon}{\operatorname{Pr}[\text { ruim }] \mu+\varepsilon} \quad \operatorname{Pr}[$ ruim $\mid$ venda $]=\frac{\operatorname{Pr}[\text { ruim }](\varepsilon+\mu)}{\operatorname{Pr}[\text { ruim }] \mu+\varepsilon}$

onde $\operatorname{Pr}$ [boa] e $\operatorname{Pr}$ [ruim] representam as probabilidades de eventos com informações boas e ruins.

A competição dos agentes no mercado faz com que a publicação das ordens de compra e venda seja feita a partir da expectativa de que as transações realizadas sobre estas ordens (e, portanto, iniciadas por ordem contrária), 
gerem lucro zero. Dessa forma, o preço da oferta de compra (bid) deve ser igual ao valor esperado da moeda estrangeira condicional na história e na chegada de ordens de venda. (Easley et al, 2008, p. 188) Assim, temos que o preço de compra é dado por:

Compra $=\operatorname{Pr}[$ boa $\mid$ venda $] \bar{V}+\operatorname{Pr}[$ ruim $\mid$ venda $] \underline{V}+\operatorname{Pr}[$ sem inf. $\mid$ venda $] V^{*}(28)$

$$
=V^{*}+(\bar{V}-\underline{V}) \frac{\delta \operatorname{Pr}[\text { boa }] \varepsilon-(1-\delta) \operatorname{Pr}[\text { ruim }](\varepsilon+\mu)}{\operatorname{Pr}[\text { ruim }] \mu+\varepsilon}
$$

onde $V^{*}=(1-\delta) \bar{V}-\delta \underline{V}$ denota a expectativa não condicional do valor da moeda estrangeira, de modo que $\bar{V}$ e $\underline{V}$ representam o valor esperado da moeda estrangeira condicional em boas e más informações, respectivamente. $\operatorname{Pr}[\mathrm{sem}$ informação $\mid$ venda $]=1-\operatorname{Pr}[$ boa $\mid$ venda $]-\operatorname{Pr}[$ ruim $\mid$ venda $]$ é a probabilidade de um evento sem informação.

O mesmo raciocínio vale para as cotações de venda (ask) em resposta a ordens de compra. As probabilidades de eventos de informações boas e ruins condicionais nas ordens de compra são dadas, respectivamente, por:

$$
\operatorname{Pr}[\text { boa } \mid \text { compra }]=\frac{\operatorname{Pr}[\text { boa }](\varepsilon+\mu)}{\operatorname{Pr}[\text { boa }] \mu+\varepsilon} \quad \operatorname{Pr}[\text { ruim } \mid \text { venda }]=\frac{\operatorname{Pr}[\text { ruim }] \varepsilon}{\operatorname{Pr}[\text { boa }] \mu+\varepsilon}
$$

E o preço da ordem de venda (ask) é dado por:

$$
\text { Venda }=V^{*}+(\bar{V}-\underline{V}) \frac{\delta \operatorname{Pr}[\text { boa }](\varepsilon+\mu)-(1-\delta) \operatorname{Pr}[\text { ruim }] \varepsilon}{\operatorname{Pr}[\text { boa }] \mu+\varepsilon}
$$

Considerando que cada dia inicia com probabilidades não condicionais de eventos de boa e má informação dadas por:

$$
\begin{gathered}
\operatorname{Pr}[\text { boa }]=(1-\delta) \alpha \\
\operatorname{Pr}[\text { ruim }]=\delta \alpha
\end{gathered}
$$

Então o spread de abertura entre bid e ask de cada dia pode ser escrito da seguinte forma:

$$
\text { Spread }=(\bar{V}-\underline{V}) \delta(\delta-1) \alpha \mu \frac{(\alpha \mu+2 \varepsilon)}{((1-\delta) \alpha \mu+\varepsilon)(\delta \alpha \mu+\varepsilon)}
$$

Se os eventos informativos bons e ruins têm a mesma probabilidade de ocorrência, ou seja, $\delta=(\delta-1)$, então o spread entre as ordens de compra e venda do início do dia passa a ter a seguinte forma: 


$$
\text { Spread }^{*}=\frac{\alpha \mu}{\alpha \mu+2 \varepsilon}(\bar{V}-\underline{V})
$$

O primeiro termo da equação (35) é a probabilidade de que a primeira transação do dia seja baseada em informação, denominada na literatura por PIN. As estimativas dos parâmetros $\theta=(\alpha, \delta, \varepsilon, \mu)$ nos permitem analisar o efeito da informação sobre o spread e, portanto, sobre a liquidez do mercado. Valores altos do PIN geram spreads maiores entre bid e ask, e um alto custo para os agentes não informados.

\subsubsection{Função de Verossimilhança}

Para obtermos a probabilidade de uma transação ser informativa precisamos estimar os parâmetros $\theta=(\alpha, \delta, \varepsilon, \mu)$. Como não é possível observar a chegada de qualquer evento informativo, a estimação conjunta destes parâmetros se torna mais complexa do que seria a estimação individual de cada uma deles.

O modelo de Easley et al (1996) assume que os dados observados de compras e vendas revelam a estrutura informacional necessária para a estimação de $\theta$. Em dias com eventos bons, espera-se mais compras; e em dias com más notícias, mais vendas. De forma análoga, nos dias em que não há eventos informativos, nenhum agente informado chega ao mercado e, portanto, espera-se menos transações. Estas taxas e probabilidades são determinadas por um modelo misto, onde o peso de cada componente (boas notícias, más notícias e sem evento informativo) reflete sua probabilidade de ocorrência $(\alpha(1-\delta), \alpha \delta,(1-\alpha)$, respectivamente).

De acordo com este modelo, a probabilidade de observarmos o número $B$ de compras e $S$ de vendas em qualquer dia é dada por:

$$
\begin{array}{rcc}
\operatorname{Pr}\left[y_{t}=(B, S)\right] & = & \alpha(1-\delta) e^{-(\mu+2 \varepsilon) \frac{(\mu+\varepsilon)^{B}(\varepsilon)^{S}}{B ! S !}} \\
& + & \alpha \delta e^{-(\mu+2 \varepsilon) \frac{(\mu+\varepsilon)^{S}(\varepsilon)^{B}}{B ! S !}} \\
+ & (1-\alpha) e^{-(2 \varepsilon) \frac{\left.()^{S}\right)^{S}+B}{B ! S !}}
\end{array}
$$

onde $y_{t}$ é o vetor de observação (número de compras e vendas) do dia $t$. Em cada dia, a chegada de um evento informativo e o número de transações condicionais nestes eventos seguem uma distribuição independente e identicamente distribuída.

A função agregada do log verossimilhança é construída a partir da soma dos logaritmos das probabilidades condicionais diárias, e é dada por:

$$
\left(\left\{y_{t}\right\}_{t=1}^{T} \mid \theta\right)=\sum_{t=1}^{T} \ln \operatorname{Pr}\left[y_{t}=\left(B_{t}, S_{t}\right)\right]
$$

onde $T$ representa o número de observações diárias e $\theta$ denota o vetor de parâmetros do modelo, $\theta=(\alpha, \delta, \varepsilon, \mu)$. As estimativas destes parâmetros são obtidas através da maximização da função agregada (37). 
Ainda que esta seja uma estimação direta e simples, quando trabalhamos com mercados muito líquidos onde o número de compras e vendas é muito alto - como o caso do mercado de câmbio - encontramos alguns problemas numéricos. Como os três componentes da equação (36) possuem os fatoriais das compras e vendas no denominador e seus numeradores aumentam conforme aumenta o total das compras e vendas, as estimativas geram erros muito altos tanto para o numerador quanto para o denominador.

Seguindo a estratégia utilizada por Easley et al (2008), fatoramos o termo que os três componentes da equação (36) possuem em comum, $e^{-2 \varepsilon} \frac{(\mu+\varepsilon)^{B_{t}+S_{t}}}{B_{t} ! S_{t} !}$, de modo que a função log de máxima verossimilhança seja dada por:

$$
\begin{aligned}
\left(\left\{y_{t}\right\}_{t=1}^{T} \mid \theta\right)= & \sum_{t=1}^{T}\left[-2 \varepsilon+\left(B_{t}+S_{t}\right) \ln (\mu+\varepsilon)-\ln \left(B_{t} ! S_{t} !\right)\right] \\
& +\sum_{t=1}^{T} \ln \left[\alpha(1-\delta) e^{-\mu} x^{S_{t}}+\alpha \delta e^{-\mu} x^{B_{t}}+(1-\alpha) x^{B_{t}+S_{t}}\right]
\end{aligned}
$$

$\operatorname{com} x=\frac{\varepsilon}{\mu+\varepsilon} \in[0,1]$.

A estimação da função (38) é relativamente simples, e gera os mesmos resultados da equação (37).

\section{Base de Dados}

A base de dados objeto deste trabalho compreende as operações do primeiro vencimento dos contratos futuros de Real/Dólar da Bolsa de Mercadorias e Futuros (BM\&F). As operações incluem as ordens de compra e venda e as negociações realizadas, com seus respectivos preços e quantidades (propostos e transacionados). A base de dados especifica cada operação na precisão do milésimo de segundo em que ocorre. O período analisado é de 06/06/2011 à 05/09/2011. O formato da base de dados por ser visualizado na Tabela 1.

Para o propósito deste estudo, o conjunto de dados está baseado na seqüência de pontos discretos que representam os eventos de mercado, indexados por $t^{13}$. Um evento ocorre quando é realizada uma transação. A variável de preço $p_{t}$ foi construída a partir da média ponderada entre as melhores cotações de compra e venda $^{14}$ existente no mercado em $t-1$. A ponderação é feita pelo inverso da quantidade proposta, uma vez que quando uma proposta de compra é muito maior, em volume, do que a de venda, então a de venda tem uma probabilidade maior de ser executada.

\footnotetext{
${ }^{13}$ Este conjunto de dados é conhecido como event time data set.

${ }^{14}$ As melhores cotações de compra e venda existentes são dadas pelo topo do book em cada momento.
} 
As transações resultam de ordens de mercado que acertam estas cotações. A variável de quantidade, representada pelo fluxo de ordem $x_{t}$, é construída dando sinal ao volume negociado. A determinação da direção de cada transação foi feita seguindo o algoritmo de classificação das transações conhecido na microestrutura como 'quore rule', similar à metodologia utilizada por Hasbrouck (1991a). Nele, uma transação cujo preço é superior à cotação média (aritmética simples) que prevalecia no mercado no evento anterior $(t-1)$, é interpretada como sendo uma compra e, portanto, seu sinal é positivo; e vice-versa para preços de transação inferiores. Se o preço da transação é exatamente igual a cotação média de compra e venda, então a transação é indeterminada e $x_{t}=0^{15}$.

\footnotetext{
${ }^{15}$ Nesta base de dados não houve nenhum caso em que a transação foi classificada como indeterminada.
} 


\begin{tabular}{|c|c|c|c|c|}
\hline $55=D O L U 11$ & $52=20110801-12: 00: 01.423$ & $269=2$ & $270=1559$ & $271=5$ \\
\hline $55=D O L U 11$ & $52=20110801-12: 00: 01.423$ & $269=Z$ & $270=1558.5$ & $271=15$ \\
\hline $55=D O L U 11$ & $52=20110801-12: 00: 01.423$ & $269=X$ & $270=1559$ & $271=100$ \\
\hline $55=D O L U 11$ & $52=20110801-12: 00: 07.903$ & $269=1$ & $270=1559$ & $271=25$ \\
\hline $55=D O L U 11$ & $52=20110801-12: 00: 07.903$ & $269=X$ & $270=1559$ & $271=125$ \\
\hline $55=D O L U 11$ & $52=20110801-12: 00: 07.963$ & $269=1$ & $270=1560$ & $271=200$ \\
\hline $55=D O L U 11$ & $52=20110801-12: 00: 08.003$ & $269=0$ & $270=1550$ & $271=5$ \\
\hline $55=D O L U 11$ & $52=20110801-12: 00: 08.003$ & $269=0$ & $270=1550$ & $271=5$ \\
\hline $55=D O L U 11$ & $52=20110801-12: 00: 08.033$ & $269=0$ & $270=1552.5$ & $271=20$ \\
\hline $55=D O L U 11$ & $52=20110801-12: 00: 08.053$ & $269=0$ & $270=1546$ & $271=15$ \\
\hline $55=D O L U 11$ & $52=20110801-12: 00: 08.063$ & $269=1$ & $270=1563$ & $271=100$ \\
\hline $55=D O L U 11$ & $52=20110801-12: 00: 08.073$ & $269=2$ & $270=1558.5$ & $271=15$ \\
\hline $55=D O L U 11$ & $52=20110801-12: 00: 08.073$ & $269=1$ & $270=1558.5$ & $271=225$ \\
\hline $55=D O L U 11$ & $52=20110801-12: 00: 08.073$ & $269=Z$ & $270=1558$ & $271=25$ \\
\hline
\end{tabular}

Nota: Os dados originais da BM\&F seguem a especificação de mensagens FIX. A primeira especifica qual o ativo que está sendo

transacionado (primeiro vencimento do contrato de dólar). A segunda coluna contém a data e horário em que a operação foi

realizada. O tipo de operação é especificado na terceira coluna, cujos índices 0 e 1 representam as ordens de compra e venda, respectivamente; o índice 2 especifica as negociações; e os índices $\mathrm{Z}$ e X representam o topo do book de compras e topo do,

book de vendas respectivamente. A quarta coluna determina o preço da operação e a quinta, o seu volume.

Tabela 2 - Estatísticas Descritivas

\begin{tabular}{rrr}
\hline & Retorno $\left(r_{t}\right)$ & Fluxo de Ordem $\left(x_{t}\right)$ \\
Média & $-8,02 * 10^{-9}$ & $-2,75$ \\
Mínimo & $-4,38 * 10^{-3}$ & $-1,00 * 10^{4}$ \\
Máximo & $4,38 * 10^{-3}$ & $1,00 * 10^{4}$ \\
Desvio Padrão & $9,24 * 10^{-5}$ & $1,53 * 10^{2}$ \\
Variância & $8,54 * 10^{-9}$ & $2,33 * 10^{4}$ \\
Assimetria & $-7,14 * 10^{-2}$ & $-4,48$ \\
Curtoses & $7,88 * 10^{1}$ & $5,79 * 10^{2}$ \\
Observações & 406.445 & 406.455 \\
\hline
\end{tabular}

A análise feita a seguir exclui os retornos overnight e as negociações de abertura e, assim, para o cálculo das autoregressões, as defasagens das transações e do retorno das cotações anteriores à primeira observação do dia são consideradas nulas, iguais a zero. Trabalha-se com a hipótese de que o processo recomeça no início de cada dia. Esta convenção facilita as análises "intradiárias".

A variável de preço é especificada em logaritmos. Esta determinação justificase através da hipótese de que medidas proporcionais são mais fáceis de serem reportadas. O fato da variável de quantidade, representada pelo fluxo de ordem, assumir valores negativos impossibilita a transformação logarítmica desta variável. Os resultados, portanto, terão uma interpretação um pouco alterada. A cada compra realizada, o retorno aumenta $\operatorname{em} \beta x_{t} \%$, ou seja, aumenta o valor referente ao coeficiente vezes o tamanho da compra, ao invés de aumentar apena $\beta \%$.

A Tabela 2 apresenta as estatísticas descritivas dos retornos das cotações e do fluxo de ordem para toda a amostra (406,445 observações). A primeira e a quinta linhas mostram o primeiro e o segundo momentos de ambas as variáveis, enquanto que a sexta e a sétima linhas indicam o terceiro e quarto momentos. Como as variáveis apresentam escalas muito distintas, os resultados se tornam de 
difícil interpretação. Para resolver este problema, optou-se por utilizá-las de forma padronizada tal que:

$$
x_{t}^{*}=\frac{x_{t}-\bar{x}}{\sigma_{x}} \text { e } r_{t}^{*}=\frac{r_{t}-\bar{r}}{\sigma_{r}}
$$

onde $\bar{x}$ e $\bar{r}$ são as médias de todas as observações de $x_{t}$ e $r_{t}$, respectivamente; e $\sigma_{x}$ e $\sigma_{r}$ representam os respectivos desvios padrões. Esta transformação faz com que ambas as variáveis passem a ter média zero e desvio padrão igual à unidade. Os resultados, como veremos a seguir, não são afetados por esta transformação. Apenas passam a ser mais fáceis de serem interpretados.

Os Gráficos 3 e 4 mostram a evolução das séries do fluxo de ordem e do log do retorno das cotações $\left\{x_{t}^{*}, r_{t}^{*}\right\}$. As figuras mostram uma forte reversão à media de ambas as variáveis, sinalizando que a hipótese de estacionariedade conjunta das séries é válida. A Tabela 3 apresenta os testes de raiz unitária de Dickey Fuller Aumentado e de Philips Perron. Os resultados dos testes indicam que a hipótese nula de raiz unitária deve ser rejeitada ao nível de significância de $1 \%$ para ambas a séries, revelando que a estacionariedade delas está assegurada. A utilização das variáveis determinadas na equação (39) não altera os resultados encontrados para as variáveis originais, que encontram-se no Apêndice.

Figura 3

Série do Log do Retorno das Cotações de Ordens de Compra e Venda.

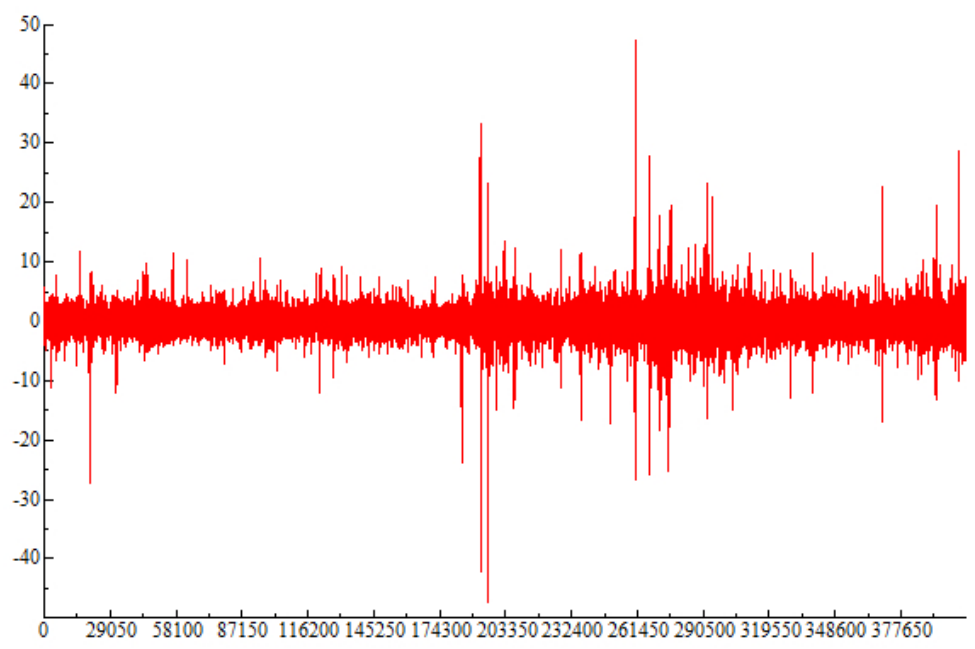

A Tabela a seguir apresenta as estatísticas de teste para a hipótese nula de não estacionariedade das variáveis. ADF representa o teste de Dickey Fuller Aumentado; e PP, o teste de Philipps Perron. 
Figura 4

Fluxo de Ordem

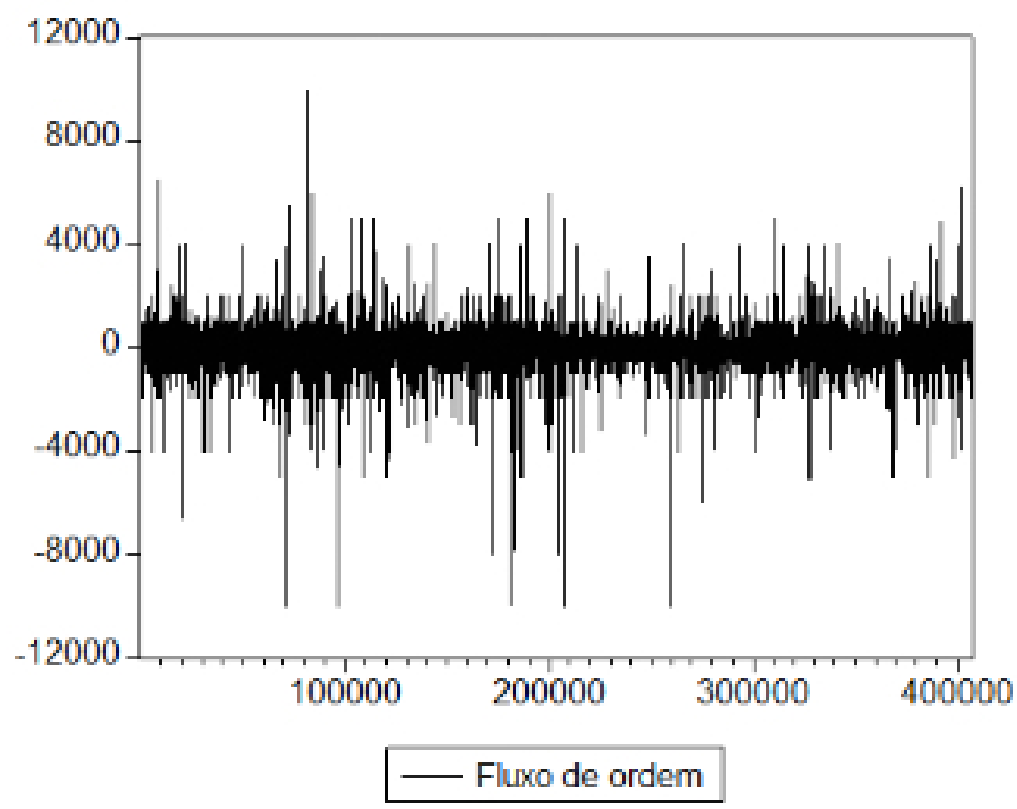

Tabela 3 - Teste de Raízes Unitárias

Estatísticas de Teste

\begin{tabular}{rrrrr}
\hline & ADF & p-valor & PP & p-valor \\
\hline Retorno & $-383,94$ & $<0,001$ & $-682,16$ & $<0,001$ \\
Fluxo de Ordem & $-158,71$ & $<0,001$ & $-616,09$ & $<0,001$ \\
\hline
\end{tabular}

\section{Resultados}

Nesta seção são apresentados os resultados obtidos através da estimação do VAR determinado na seção 3.1, da decomposição da variância apresentada na seção 3.2 e do cálculo do PIN na seção 3.3. Serão apresentados primeiro os resultados para toda a amostra para, em seguida, serem feitas as análises sobre as estimações das três sub-amostras não sobrepostas. A análise de sub-amostras objetiva confirmar a hipótese sugerida por Adamati e Pfleiderer (1988) de que em períodos de maiores volumes, o impacto das transações sobre os preços é menor. As variáveis utilizadas, e já discutidas anteriormente, são os retornos percentuais da cotação média das ofertas de compra e venda do câmbio Real/Dólar $\left(r_{t}^{*}\right)$, e o volume transacionado com sinal indicador da parte iniciante do negócio $\left(x_{t}^{*}\right)$. 
Uma das hipóteses cruciais deste modelo é de que as perturbações $\left(\varepsilon_{1, t} \mathrm{e} \varepsilon_{2, t}\right)$ não são correlacionadas com os regressores (defasagens de $x_{t}$ e $r_{t}$, e o termo contemporâneo de $x_{t}$ na equação 14). A estacionariedade conjunta do retorno das cotações e das transações $\left\{x_{t}^{*}, r_{t}^{*}\right\}$ vista anteriormente permite, através do Teorema de Wold, que o modelo possa ser escrito como um processo de médias móveis (VMA) de ordem infinita. Se a representação VMA é invertível, então, por definição, as séries possuem uma representação autoregressiva (VAR) infinita, e as equações (14) e (15) valem, cujos coeficientes convergem.

A primeira linha da Tabela 4 apresenta os parâmetros do VAR bivariado ${ }^{16}$ estimado na sua forma reduzida através de 15 defasagens ${ }^{17}$ para a amostra inteira. O mais importante conjunto de coeficientes são os efeitos das defasagens de $x_{t}^{*}$ na equação do retorno das cotações $r_{t}^{*}$, que se mostraram, em sua maioria, positivos e significativos. A soma destes coeficientes, que pode ser vista na quinta coluna da Tabela 4, também se mostrou positiva e significativa, indicando que uma compra (uma transação iniciado por um comprador que acerta uma ordem de venda préestabelecida no mercado, $x_{t}^{*}>0$ ) eleva o retorno das cotações, em média. A significância global de todos os parâmetros encontrada a partir do teste de Wald indica uma relação de Granger causalidade de $x_{t}^{*}$ para $r_{t}^{* 18}$

\footnotetext{
${ }^{16}$ Como os dados não são igualmente espaços podemos ter problemas de microestutura que podem ser resolvidos usando uma especificação médias-móveis (MA) para os erros. Isto não foi feito mas os estimadores obtidos continuam consistentes uma vez que a estrutura MA dos erros pode ser reescrita como VAR. Deste modo como usamos o critério de Akaike, que superparametriza o modelo, este aumento de defasagem controla, parcialmente, a estutura MA dos erros, minimizando o problema de micro-estrutura.

${ }^{17}$ A escolha da ordem do VAR foi feita através da análise de critérios de informação. O critério selecionado foi o de Akaike, mesmo que este tenda a superestimar os parâmetros. Isto porque o modelo com número de defasagens sugerido pelo critério de Schwarz apresentou autocorrelação serial e, portanto, se mostrou mal especificado.

${ }^{18} \mathrm{O}$ teste de Wald feito para verificar a significância global dos coeficientes defasados do fluxo de ordem na equação do retorno resultou numa estatística de teste $\mathrm{F}$ de 38.30 , de forma que a hipótese nula de que todos os coeficientes são iguais a zero conjuntamente fosse rejeitada ao nível de significância de $1 \%$.
} 


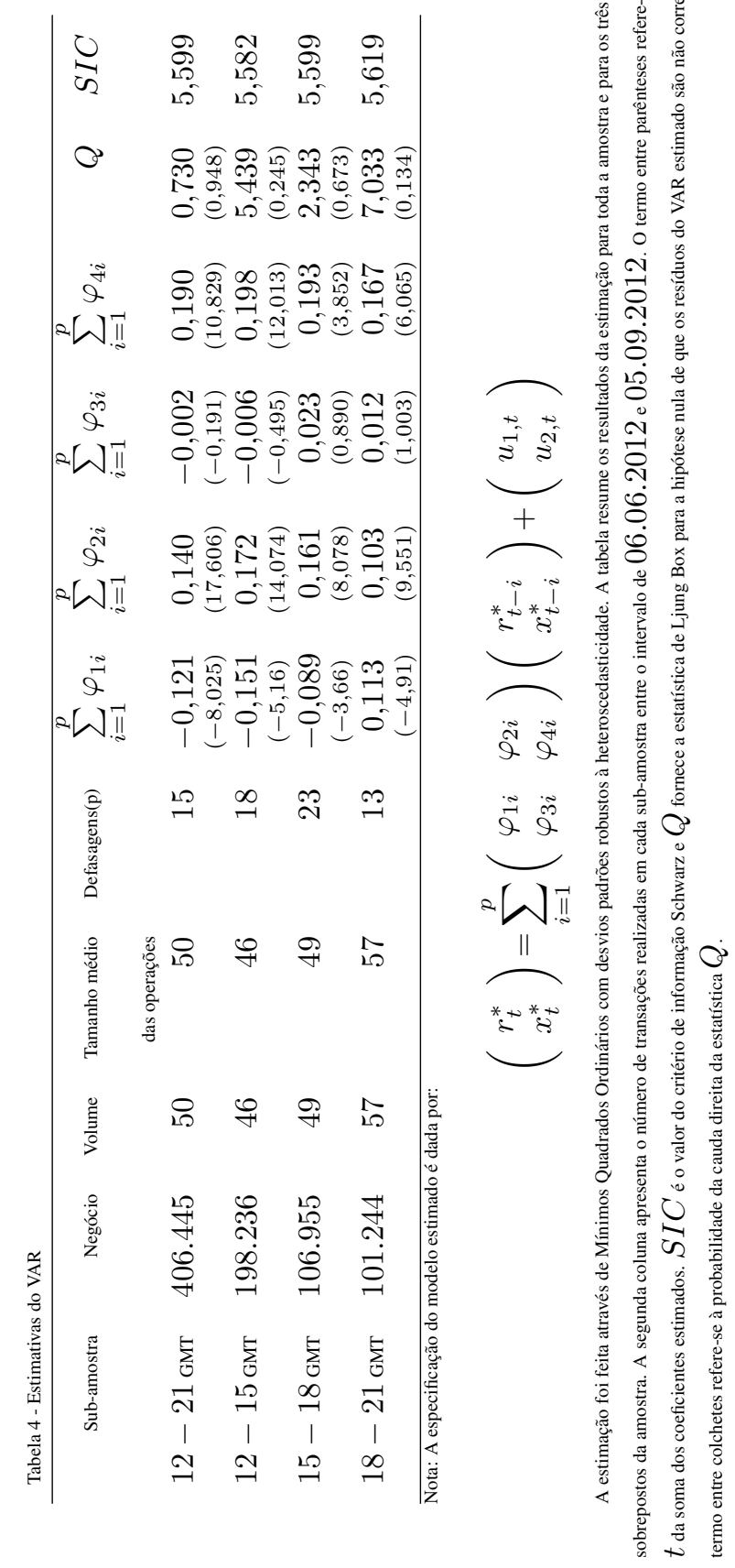


Outra importante característica evidenciada pela estimação do modelo é a autocorrelação positiva das transações refletida pelos coeficientes das defasagens de $x_{t}^{*}$ na própria equação de $x_{t}^{*}$, e ratificada pela soma positiva e significativa dos coeficientes $\varphi_{4 i}$. Em linha com Payne (1999), Hasbrouck (1991b), Hasbrouck (1988) e Hasbrouck e Ho (1987), este resultado indica que compras tendem a seguir compras e o mesmo vale para vendas. No curto prazo, isto pode ser decorrente dos ajustes defasados que ocorrem a cada chegada de nova informação no mercado. Além disso, a autocorrelação positiva pode estar associada, em certa medida, ao fato dos agentes fazerem split de suas ordens de maiores volumes.

Os resultados apresentados acima - o impacto positivo das transações sobre os retornos e autocorrelação positiva das transações - são os principais fatores determinantes da trajetória dinâmica de ajustamento do modelo. Mas outras características importantes podem também ser avaliadas através da Tabela 4. A dinâmica dos retornos não mostrou ter efeito sobre as transações uma vez que a soma dos coeficientes $\varphi_{3 i}$ não tenha se mostrado significativa. Isto indica que em mercados de ordem limite não existe um market maker monopolista que consiga influenciar as compras (ou vendas) através apenas da administração de suas próprias cotações no mercado, dado um superávit de inventário. A autocorrelação significativa e negativa dos retornos foi também verificada no trabalho de Payne (1999) para o mercado de dólar/marco.

Os parâmetros do VAR estrutural representado nas equações (14) e (15) podem ser facilmente recuperados através dos coeficientes da forma reduzida, uma vez que são funções lineares destes. Os coeficientes identificados por $\beta_{i}$ na equação (14) representam os efeitos das transações nos retornos correntes e subseqüentes das cotações. A soma destes coeficientes é positiva, indicando predominância positiva dos coeficientes individuais.

A Tabela 5 apresenta os parâmetros da representação VMA identificada pela equação (22). A medida do impacto cumulativo e persistente das transações sobre os preços é obtida através das funções de impulso resposta do retorno das cotações em relação às inovações do fluxo de ordem ao longo de todos os períodos, $\sum_{k=0}^{\infty} b_{k}$. A terceira coluna da Tabela 6 indica que este impacto cumulativo é próximo a 0,102 , o que equivale a dizer que o acúmulo de compras não esperadas de $U S \$$ 50.000 no mercado aumenta o retorno das cotações em 0,1 pontos percentuais após 15 períodos.

A importância relativa da informação do fluxo de ordem é capturada a partir da decomposição da variância do termo permanente (eficiente) em dois componentes, um relacionado às transações e outro que não tem relação com elas. Os resultados estão dispostos também na Tabela 5. Segundo as estimativas feitas, aproximadamente $50 \%$ da variância do retorno permanente é atribuída à informação privada. Este é um resultado superior àquele encontrado por Payne (1999) para o mercado de dólar/marco alemão de $40 \%$, e superior aos resultados encontrados na literatura 
internacional para o mercado de ações, como Hasbrouck (1991a) que encontrou um valor médio de $34 \%$ para ações dos EUA, e De Jong, Nijman e Röell (1995) cujo valor encontrado para ações francesas foi também de $40 \%$. 


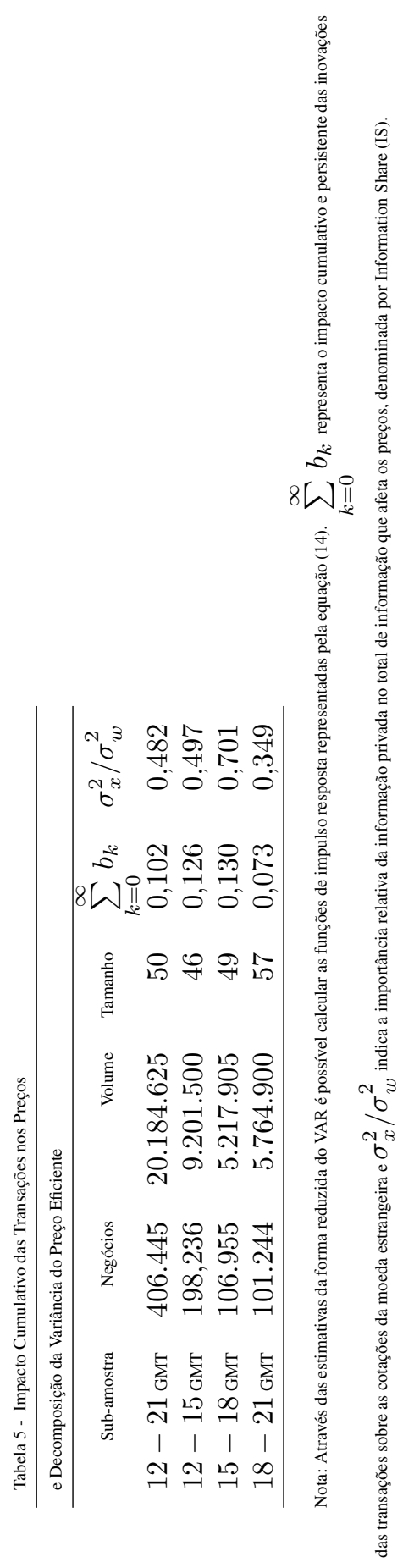

@) (1) Rev. Bras. Finanças (Online), Rio de Janeiro, V14, No. 1, March 2016 
A hipótese de que o impacto da informação privada sobre os preços da moeda estrangeira sofre alterações ao longo do dia em decorrência das flutuações do volume negociado entre os agentes é analisada através das estimações descritas acima em períodos não sobrepostos do dia. Segundo Adamati e Pfleiderer (1988), o padrão de volumes maiores no início e no final do dia - conhecido como formato $U$ - é bem comum em diversos mercados e já está bem documentado na literatura.

Adamati e Pfleiderer (1988) mostram que a partir do momento em que existe um agente informado no mercado, a introdução de mais agentes informados normalmente intensifica a concentração daqueles que não recebem sinais de informação, e que transacionam por motivos de liquidez. Isto porque os agentes informados competem entre si e esta competição aumenta o bem estar dos agentes não informados. Portanto, seu modelo de aquisição endógena de informação sugere que períodos de volumes maiores sejam caracterizados por impactos menores das transações sobre os preços.

A análise das estimativas das sub-amostras indica que o conteúdo informacional parece ter uma relação inversa com o volume transacionado, corroborando a hipótese teórica de Adamati e Pfleiderer (1988). Os efeitos das transações defasadas sobre os preços, na Tabela 4, são menores no período de maior volume (18-21 GMT), assim como o impacto cumulativo do componente inesperado do fluxo de ordem $\sum_{k=0}^{\infty} b_{k}$, da Tabela 5 .

A decomposição da variância para as três sub-amostras segue a mesma lógica. Quanto maior a concentração de agentes negociando no mercado, ou seja, quanto maior o volume negociado, menor a importância da informação privada na variação total do retorno.

A observação do fluxo de ordem também permite calcular a probabilidade de ocorrência de transações baseadas em informação. Com base nos quatro parâmetros fundamentais do processo de transação $-\alpha$, a probabilidade de um evento informativo; $\delta$, a probabilidade de que a informação é ruim; $\mu$, a taxa de chegada de ordem dos agentes que conhecem a nova informação; e $\varepsilon$, a taxa de chegada de ordens de agentes não informados - é possível calcular a probabilidade de uma transação ser iniciada por um agente que dispõe de informação privada no próximo dia, e sua relação com o spread. O conhecimento desta medida no mercado de câmbio é importante para a gestão do risco associado à reversão de posições tomadas neste mercado.

As estimativas dos parâmetros $\theta=(\alpha, \delta, \mu, \varepsilon)$ foram feitas através da maximização da função de verossimilhança condicional descrita na seção 3.4. As probabilidades $(\alpha, \delta)$ foram restringidas ao intervalo $(0,1)$, enquanto que as taxas de chegada de ordens $(\mu, \varepsilon)$ puderam variar no intervalo $(0, \infty)$. Os resultados se mostraram bem sensíveis aos valores iniciais usados para os parâmetros. Para resolver essa questão, optou-se, neste trabalho, por utilizar o algortimo genético - que determina pontos próximos da solução ótima - como gerador dos pontos iniciais da maximização em questão. 
A Tabela 6 fornece as estimativas desses parâmetros. A taxa de chegada de ordens de agentes não informados é de aproximadamente 3.078, enquanto que esta mesma taxa para as ordens postadas por agentes informados é de 220 . Ou seja, a cada dia, 3.078 ordens de compra/venda chegam ao mercado postadas por agentes que não dispõem de informação superior, enquanto que a proporção das ordens originadas por agentes informados é bem menor, apenas de $7 \%$ desta taxa. A probabilidade de haver um evento informativo se aproxima de $40 \%$, mas quando este ocorre, a probabilidade de más notícias é bem superior à de boas notícias, chegando a $60 \%$.

Tabela 6 - Estimativas das Taxas de Chegadas e do PIN

\begin{tabular}{rrrcc}
\hline PIN & $\varepsilon$ & $\mu$ & $\alpha$ & $\delta$ \\
\hline $1,53 \%$ & $3.078,3$ & 220,1 & 0,4 & 0,6 \\
& $(15,88)$ & $(20,38)$ & $(1,61)$ & $(2,45)$ \\
\hline Nota: Esta tabela apresenta a estimativa da probabilidade de uma transação ser informativa (PIN), que é composta pelas estimativas
\end{tabular}

dos parâmetros do processo de transação. O parâmetro $\alpha$ é a probabilidade de ocorrência de um evento informativo; $\delta$, a probabilidade de que a informação seja ruim (condicional na ocorrência do evento informativo); $\mu$, a taxa de chegada de ordens dos agentes que conhecem a nova informação; e $\varepsilon$, a taxa de chegada de ordens de agentes não informados. Os valores entre parênteses informam a estatística-t de cada estimativa obtida através do método de Bootstrap após 500 replicações.

A análise da estatística t-Student de cada parâmetro, representada entre parênteses, nos possibilita inferir que estas estimativas são bem precisas. Os erros padrões são calculados a partir da distribuição assintótica dos parâmetros, utilizando-se o método de Bootstrap com 500 replicações. Dentre todos os parâmetros, as taxas de chegada são as estimativas obtidas com maior exatidão, explicada pelo alto número de transações realizadas por dia no mercado de câmbio.

A probabilidade de transação informativa é uma composição dos parâmetros que caracterizam o processo de transação. O resultado da interação dos parâmetros estimados acima é também apresentado na Tabela 6. A probabilidade da primeira transação do dia ser iniciada por um agente com informação superior é de aproximadamente 1,53\%. Esta é uma medida simples de liquidez de mercado. Altos valores implicam spreads mais amplos, maiores custos de transação para os agentes não informados, e menor liquidez do mercado. Portanto, um resultado de 1,53\% indica que o mercado de câmbio brasileiro é bastante líquido e impõe menores custos aos agentes menos informados que chegam ao mercado.

\section{Conclusões}

Neste artigo foi proposta uma análise sobre a hipótese de assimetria de informação no mercado cambial brasileiro através da inferência sobre os efeitos permanentes do conteúdo informacional privado das transações sobre os preços de equilíbrio da moeda estrangeira.

Conclusões encontradas na literatura nacional de que a taxa de câmbio brasileira é formada primeiramente no mercado futuro para ser repassada, via arbitragem de juros, ao mercado à vista, serviram de arcabouço teórico para a decisão de 
investigar a hipótese de assimetria de informação nas operações do primeiro vencimento dos contratos futuros de câmbio Real/Dólar, disponibilizadas pela Bolsa de Mercadorias e Futuros (BM\&F).

Utilizando a tecnologia do vetor auto-regressivo (VAR) estrutural introduzida por Hasbrouck (1991a, 1991b), encontramos evidências de que os agentes deste mercado são assimetricamente informados e que o impacto cumulativo da informação privilegiada (carregada pelas transações) sobre os níveis de preço é positivo, de forma que compras inesperadas de US\$ 50.000 levam a aumentos de 0,1 ponto percentual do retorno das cotações. $\mathrm{O}$ contrário vale para as vendas não antecipadas pelo mercado.

Uma medida da importância relativa da informação privada transmitida ao mercado através das transações foi criada a partir da decomposição da variância do modelo VAR. Os resultados mostraram que aproximadamente $50 \%$ da variação do preço eficiente é atribuída às inovações do fluxo de ordem, o que nos permite concluir que os efeitos de informação privada sobre os preços são de fato permanentes e, portanto, caracterizam assimetria de informação.

O trabalho também analisou a variação do conteúdo informacional ao longo do dia em decorrência das flutuações do volume negociado entre os agentes. Em linha com a hipótese apontada por Adamati e Pfleiderer (1988), podemos concluir que a concentração de agentes no mercado (maiores volumes negociados) reduz tanto o impacto cumulativo das transações sobre os preços quanto a importância da informação privada na variação total do preço eficiente, uma vez que ambos tenham apresentado uma relação inversa com o tamanho médio das operações negociadas.

Por fim, as estimativas das taxas de chegadas de ordens de agentes informados e não informados no mercado, obtidas através da otimização da função de máxima verossimilhança, permitiram o cálculo da probabilidade de uma transação ser informativa (PIN). Altos valores de PIN implicam spreads mais amplos que reduzem a liquidez do mercado. Portanto, um resultado de $1,53 \%$ indica que o mercado de câmbio brasileiro é bastante líquido, o que impõe menores custos aos agentes menos informados que chegam neste mercado.

\section{Referências}

Abuaf, Niso \& Jorion, Philippe (1990) Purchasing Power Parity in the Long Run. The Journal of Finance, 45, 157-174.

Adamati, Anat R. \& Pfleiderer, Paul (1988) A Theory of Intra-Day Patterns: Volume and Price Variability. Review of Financial Studies, 1(1), 5-40.

Cavalcanti, Marco A. F. H. (2010) Identificação de Modelos VAR e Causalidade de Granger: Uma nota de advertência. Economia Aplicada, 14 (2), 251-260.

Dornbush, Rudiger (1976) Expectations and exchange rate dynamics. Journal of Political Economy, 84, 1161-1176. 
De Jong, Frank; Nijman, Theo \& Röell, Ailsa (1995) Price Effects of Trading and Components of the Bid-Ask Spread on the Paris Bourse. Discussion Paper 207, Financial Markets Group, London School of Economics.

De Jong, Frank. \& Rindi, Barbara (2009) The Microstructure of Financial Markets. Cambridge University Press. Cambridge.

Evans, Martin. D. D. \& Lyons, Richard. K. (2002) Order Flow and Exchange Rate Dynamics. The Journal of Political Economy, 110 (1), 170-180.

Easley, David \& O'Hara, Maureen (1987) Price, Trade Size and Information in Securities Markets. Journal of Financial Economics, 19, 69-90.

Easley, David \& O'Hara, Maureen (1992) Time and the Process of Security Price Adustment. Journal of Finance, 47, 577-606.

Easley, David; Kiefer, Nicholas M. ; O’Hara, Maureen \& Paperman, Joseph B. (1996) Liquidity, Information, and Infrequently Traded Stocks. The Journal of Finance, 50, 1405-1436.

Easley, David; Engle, Robert F.; O’Hara, Maureen \& Wu, Liuren (2008) TimeVarying Arrival Rates of Informed and Uninformed Trades. Journal of Financial Econometrics, 6 (2), 171-207.

Fernandes, André V. (2008) Microestrutura do Mercado Cambial Brasileiro: Comparação do mercado à vista e futuro. Rio de Janeiro: PUC-Rio. Dissertação (Mestrado) Programa de Pós-Graduação em Economia, Pontifícia Universidade Católica, Rio de Janeiro.

Flood, Robert P. \& Taylor, Mark P. (1996) Exchange rate economics: What's wrong with the conventional macro approach? Em The Microstructure of Foreign Exchange Markets, editado por J. Frankel, G. Galli e A. Giovannini. Chicago: University of Chicago Press.

Frankel, Jeffrey A. \& Rose, Andrew K. (1995) Empirical research on nominal exchange rates. Em Handbook of International Economics, editado por G. Grossman e K. Rogoff. Amsterdam: Elsevier Science.

Frenkel, Jacob A. (1976) A monetary approach to the exchange rate: Doctrinal aspects empirical evidence. Scandinavian Journal of Economics, 78, 200-224.

Garbade, Kenneth D. \& Silber, William L. (1982) Price Movements and Price Discovery in Futures and Cash Markets. Review of Economics and Statistics, 64, 289-297.

Garcia, Márcio G.P. \& Urban, Fabio (2004) O Mercado Interbancário de Câmbio no Brasil. Rio de Janeiro: Pontifícia Universidade Católica - PUC-Rio. Working Paper.

Glosten, Lawrence R. \& Milgrom, Paul R. (1985) Bid, ask and transactions prices 
in a specialist market with heterogeneously informed traders. Journal of Financial Economics, 14, 71-100.

Glosten, Lawrence R. (1987) Components of the Bid-Ask Spread and the Statistical Properties of Transaction Prices. The Journal of Finance, 42 (5), 1293-1307

Hamao, Yasushi \& Hasbrouck, Joel (1995) Securities Trading in the Absence of Dealers: Trades and Quotes on the Tokyo Stock Exchange. Review of Financial Studies, 8, 849 - 878 .

Hamilton, James D. (1994) Time Series Analysis. Princeton University Press, Princeton, New Jersey.

Harris, Lawrence (1990) Estimation of Stock Price Variances and Serial Covariances from Discrete Observations. Journal of Financial and Quantitative Analysis, 25 (3), 291-306.

Hasbrouck, Joel (1988) Trades, Quotes, Inventories and Information. Journal of Financial Economics, 22, 229-252.

Hasbrouck, Joel (1991a) The Summary Informativeness of Stock Trades: An Econometric Analysis. Review of Financial Studies, 4, 571-595.

Hasbrouck, Joel (1991b) Measuring the Information Content of Stock Trades. The Journal of Finance, 46, 733-746.

Hasbrouck, Joel (1995) One Security, Many Markets: Determining the Contributions to the Price Discovery. Journal of Finance, 50, 1175-1199.

Hasbrouck, Joel (2007) Empirical Market Microstructure: The Institutions, Economics, and Econometrics of Securities Trading. EUA: Oxford University Press.

Hasbrouck, Joel \& Ho, Thomas S. Y. (1987) Order Arrival, Quote Behavior, and the Return-Generating Process. The Journal of Finance, 42 (4), 1035-1048.

Kyle, Albert S. (1985) Continuous Auction and Insider Trading. Econometrica, 53 (6), 1315-1335.

Laurini, Márcio. P.; Furlani, Luiz G. C. \& Portugal, Marcelo S. (2008) Empirical Market Microstructure: An analysis of the BRL/US\$ Exchange Rate Market. Emerging Markets Review, 9, 247-265.

Lyons, Richard. K. (2001) The microstructure approach to exchange rates. Cambridge: MIT Press

Meese, Richard A. \& Rogoff, Kenneth (1983) Empirical exchange rate models of the seventies. Journal of International Economics, 14, 3-24.

Meredith, Guy \& Chinn, Menzie D. (1998) Long-Horizon Uncovered Interest Rate Parity. NBER Working Paper, n. 2138.

Payne, Richard (1999) Informed Traded in Spot Foreign Exchange Markets: An 
Empirical Investigation. Financial Markets Group, London School of Economics.

Rime, Dagfinn (2001) Private or Public Information in Foreign Exchange Markets? An Empirical Analysis. Stockholm Institute for Financial Research.

Taylor, Mark P. (1995) The Economics of Exchange Rates. Journal of Economic Literature, 83, 13-47.

Wu, Thomas (2010) Order Flow in the South: Anatomy of the Brazilian FX market. The North American Journal of Economics and Finance, 23 (3), 310-324. 